\title{
Artikel
}

\section{Postume rente in de wettelijke vereffening}

\author{
Mr. J.M. van Anken*
}

\section{Inleiding}

Het vereffenen van nalatenschappen lijkt soms meer kunst dan wetenschap. Met een handjevol voorschriften in Boek 4 van het Burgerlijk Wetboek (BW), voorzien van een schakelbepaling hier en daar naar de Faillissementswet $(\mathrm{Fw})$, lijkt de vereffenaar meer een abstracte richtlijn op hoofdpunten dan een uitputtende handleiding ter hand gesteld te krijgen. ${ }^{1}$ Niet alleen de vereffenaar zelf lijdt onder de terughoudendheid van de wetgever bij het geven van duidelijke voorschriften, ook de rechterlijke macht moet roeien met de riemen die ze heeft en maakt daar gelukkig ook werk van. ${ }^{2}$ Desalniettemin blijft genoeg onduidelijk. Dat blijkt eens te meer uit twee tegenstrijdige oordelen van respectievelijk het Gerechtshof Amsterdam en de rechter-commissaris bij de Rechtbank Noord-Nederland in 2017. ${ }^{3}$ Ik zet beide zaken hieronder uiteen en voorzie ze daarna van commentaar.

* Mr. J.M. van Anken is notarieel jurist bij Vechtstede Notarissen \& Mediators te Hardenberg en promovendus aan de Rijksuniversiteit Groningen, vakgroep Privaatrecht en Notarieel Recht.

1. Zie in algemene zin over de verhouding tussen het insolventierecht en het erfrecht S. Perrick, Insolventie en erfrecht, in: G.H. Lankhorst e.a., Insolventierecht in de notariële praktijk (KNB preadvies 2011), Den Haag: Sdu Uitgevers 2011, p. 265-334.

2. Zo zijn onlangs de Richtlijnen Vereffening nalatenschappen gepubliceerd, ontwikkeld door de Expertgroep Erfrecht van het Landelijk Overleg Vakinhoud Civiel, Kanton en Toezicht (LOVCK\&T), te raadplegen op www.rechtspraak.nl.

3. Respectievelijk Hof Amsterdam 28 maart 2017, ECLI:NL:GHAMS 2017:1031 en Rb. Noord-Nederland 9 augustus 2017, ECLI:NL:RBNNE: 2017:3158, Notamail 2017/208.

\section{Hof Amsterdam 28 maart 2017}

\section{$2.1 \quad$ Feiten}

Partijen zijn kinderen van erflaatster, hun moeder, die als langstlevende in een wettelijke verdeling aan haar kinderen een schuld heeft uit overbedeling. In haar eigen testament heeft moeder één van haar kinderen - appellant - onterfd en de andere twee tot erfgenaam benoemd. Omdat in de nalatenschap van moeder de schulden de baten overtreffen, hebben de erfgenamen de nalatenschap beneficiair aanvaard. Appellant vordert - voor zover relevant voor het onderwerp van deze noot - rente over de onderbedelingsvordering ter zake van de nalatenschap van vader.

\subsection{Uitspraak}

$\mathrm{Na}$ te hebben overwogen dat voor het verschuldigd worden van wettelijke rente de schuldenaar in verzuim moet zijn (art. 6:119 lid $1 \mathrm{BW}$ ) en dat dit het geval is omdat appellant heeft aangemaand en een termijn heeft gesteld (vergelijk art. 6:81 jo. 6:82 $\mathrm{BW}$ ), gaat het hof in op de vraag of rente überhaupt in rekening kan worden gebracht in de wettelijke vereffening.

Ter beantwoording van die vraag overweegt het hof dat door de beneficiaire aanvaarding de regels van vereffening in Boek $4 \mathrm{BW}$ van toepassing zijn. Bepalingen in de Fw zijn, aldus het hof, zo veel mogelijk van toepassing. Omdat voor de vereffening in Boek $4 \mathrm{BW}$ een specifieke regeling op dit punt ontbreekt, wordt aansluiting gezocht bij de regels uit de $\mathrm{Fw}$. In artikel $128 \mathrm{Fw}$ is opgenomen dat schuldeisers in beginsel in faillissement kunnen opkomen voor het bedrag dat zij op het moment van faillietverklaring te vorderen hebben. Analoge toepassing van dat artikel leidt ertoe dat vanwege (1) de toepassing van de wettelijke vereffening en (2) het feit dat de omvang (het saldo) van de nalatenschap negatief 
is, geen rente in rekening kan worden gebracht/ verschuldigd is, aldus het hof. ${ }^{4}$

\section{Rb. Noord-Nederland 9 augustus 2017}

\subsection{Feiten}

Voor zover uit de uitspraak op te maken, is sprake van een benoemde vereffenaar in de nalatenschap van (vermoedelijk) de vader van de erfgenaam. Bovendien is in die vereffening een rechter-commissaris (hierna: R-C) benoemd (zie art. 4:208 BW). De vereffenaar is voornemens het bedrijf van erflater te verkopen en vraagt daartoe goedkeuring aan de R-C. Bovendien wordt een voorschot op het loon van de vereffenaar verzocht. Dit verzoek is de erfgenaam kennelijk onwelgevallig en hij maakt bij brief bij de R-C bezwaar tegen de voorgenomen wijze van verkoop en de erkenning c.q. betwisting door de vereffenaar van een aantal vorderingen op de nalatenschap.

\subsection{Uitspraak}

De R-C overweegt als volgt. Het verzoek van de vereffenaar tot goedkeuring van de verkoop wordt door de R-C afgewezen, omdat in een op diezelfde dag gegeven aanwijzing aan de vereffenaar dienaangaande aanwijzingen zijn gegeven. Wat het voorschot betreft wordt het door de vereffenaar verzochte bedrag enigszins gematigd door aan te sluiten bij de Recofa-richtlijnen. ${ }^{5}$ De bezwaren van de erfgenaam worden op hun beurt verwezen naar de toekomst. Voor zover die bezwaren zien op de erkenning van vorderingen van anderen, verwijst de R-C naar de mogelijkheid in verzet te komen tegen de - in de toekomst bekend te maken - rekening en verantwoording en de uitdelingslijst ex artikel 4:218 lid 3 BW. Voor zover het gaat om de erkenning van de vordering van de erfgenaam zelf, verwijst de R-C naar de mogelijkheid die vordering bij vonnis te doen vaststellen ingevolge artikel 4:223 lid 2 BW.

Wel ziet de R-C en passant aanleiding iets op te merken over de berekening van rente over schulden van de nalatenschap sinds de datum van overlijden van erflater. De vereffenaar heeft namelijk ten onrechte artikel $128 \mathrm{Fw}$ van overeenkomstige toepassing geacht in de wettelijke vereffening. Dat artikel is juist niet van toepassing, aldus de R-C, omdat nalatenschappen niet worden gefixeerd zoals faillissementsboedels. De vereffenaar krijgt daarom de aanwijzing 'om bij de erkenning c.q. betwisting van vorderingen van schuldeisers op de nalatenschap tot uitgangspunt te nemen dat ook rente na de overlijdensdatum meegenomen dient te worden'.

4. Zie Hof Amsterdam 28 maart 2017, ECLI:NL:GHAMS:2017:1031, r.o. 3.26 .

5. Recofa-richtlijnen voor faillissementen en surseances van betaling, te raadplegen op www.rechtspraak.nl.

\section{Commentaar}

\subsection{Inleiding}

Twee uitspraken over hetzelfde onderwerp met verschillende uitkomst. Het hof overweegt dat rente niet kan worden meegenomen, terwijl de R-C het tegenovergestelde vaststelt. Een aantal vragen rijst, in de eerste plaats in hoeverre rente nu wel of niet kan worden meegenomen.

Een te vereffenen nalatenschap bevat dikwijls schulden waarover rente moet worden betaald. Voor zover de termijnen ingevolge waarvan die rente verschuldigd is, zijn vervallen voor overlijden, rijzen hier geen moeilijke vragen. De vervallen termijnen zijn bestaande schulden die vallen onder het bereik van artikel 4:7 lid 1 sub a BW en zij dienen op de uitdelingslijst te worden opgenomen. ${ }^{6}$ Hoe zit dat met rentetermijnen die vervallen na overlijden? Hoewel dat geen bij overlijden bestaande schulden zijn, zijn die termijnen wel schulden van de nalatenschap. ${ }^{7}$ Staat er iets in de weg aan het ter zake van die rentevorderingen nemen van verhaal op het nalatenschapsvermogen?

\subsection{Faillissement}

In het faillissementsrecht wordt deze vraag van een antwoord voorzien in artikel $128 \mathrm{Fw}$. Ingevolge dat artikel kunnen na faillissement lopende interesten slechts worden geverifieerd (opgenomen in de uitdelingslijst) indien en voor zover zij door pand of hypotheek zijn gedekt. Dat houdt in dat rentetermijnen die na het uitspreken van het faillissement vervallen, alleen in het faillissement kunnen worden geldend gemaakt voor zover de opbrengst van het verhypothekeerde of verpande goed daarvoor toereikend is. De redengeving daarvoor is blijkens de memorie van toelichting dat schuldeisers in het faillissement opkomen voor het bedrag dat zij op het ogenblik van faillissement te vorderen hebben, dat het faillissement hun rechten fixeert. ${ }^{8}$ Slechts in het geval een goed speciaal verbonden is (verhypothekeerd of verpand), bestaat aanleiding daar een uitzondering op te maken. ${ }^{9}$ Het faillissement regelt immers juist de uitoefening van ieders recht, maar brengt in die rechten zelf in beginsel geen wijziging.

\subsection{Vereffening}

De vereffening van een nalatenschap beoogt de uitoefening van rechten van bij de nalatenschap betrokkenen te regelen. De boedel en zijn liquidatie dienen in vereffening de belangen van erfgenaam en schuldeisers van de nalatenschap, ${ }^{10}$ net zoals in faillissement de boedel de belangen van de failliet en diens schuldeisers dient.

6. W.D. Kolkman, Schulden der nalatenschap (diss. Groningen), Deventer Kluwer 2006, p. 9-11.

7. Zie uitgebreider Kolkman, Schulden der nalatenschap, p. 234-241; P. Blokland, W. Burgerhart \& W.D. Kolkman, Hanteerbaar familievermogensrecht in tijden van crisis, WPNR 2013/6966.

8. S.C.J.J. Kortmann \& N.E.D. Faber (red.), Geschiedenis van de faillissementswet (heruitgave Van der Feltz I), Deventer: Wolters Kluwer 2016, p. 126.

9. Kortmann \& Faber, Geschiedenis van de faillissementswet, p. 127

10. Zie HR 19 mei 2017, ECLI:NL:HR:2017:939, r.o. 4.3.2. 
Reden genoeg te veronderstellen dat in vereffening de regel van artikel $128 \mathrm{FW}_{\mathrm{W}}$ overeenkomstig opgaat, zo zou gesteld kunnen worden. De notaris-vereffenaar heeft dat standpunt ook bij de R-C voor het voetlicht gebracht en bevindt zich daarin bovendien in het goede gezelschap van het Gerechtshof Amsterdam. ${ }^{11}$

Artikel $128 \mathrm{Fw}$ is echter niet als zodanig in Boek $4 \mathrm{BW}$ van overeenkomstige toepassing verklaard, zodat de wet geen (direct) antwoord geeft op de vraag of postume rente in de vereffening kan worden ingediend. Zoals hiervoor ter sprake gebracht, is de regel van artikel 128 $\mathrm{F}_{\mathrm{W}}$ een uitvloeisel van het fixatiebeginsel. Dat beginsel geldt niet in vereffening, aldus de $\mathrm{R}-\mathrm{C}$ in de genoemde uitspraak, en dus moet rente worden meegenomen. Erfgenamen worden immers van rechtswege schuldenaar van de schulden van de erflater die niet met zijn dood tenietgaan (art. 4:182 lid $2 \mathrm{BW}$ ) en treden in alle rechten en plichten van de erflater. ${ }^{12}$

Wat er ook zij van het standpunt dat een te vereffenen nalatenschap niet wordt gefixeerd, op de redenering van de $\mathrm{R}-\mathrm{C}$ is wel iets af te dingen. Weliswaar staat nergens in Boek 4 BW dat de nalatenschap gefixeerd dient te worden, ${ }^{13}$ maar volgens artikel 4:218 lid $5 \mathrm{BW}$ vinden '(...) bij de berekening van ieders vordering (...) de dienaangaande in de Faillissementswet voorkomende voorschriften zoveel mogelijk overeenkomstige toepassing'. Het is waarschijnlijk dit artikellid waar het hof op doelt, waar het opmerkt dat de bepalingen in de Fw zo veel mogelijk van toepassing zijn. In de parlementaire geschiedenis wordt naar voren gebracht dat deze verwijzing meebrengt dat onder meer niet-opeisbare schulden worden opgenomen in de uitdelingslijst conform artikel $131 \mathrm{FW}_{\mathrm{W}}$ en dat voorwaardelijke en niet in geld luidende schulden conform artikel 130 en $133 \mathrm{FW}_{\mathrm{W}}$ daarvoor in aanmerking komen. ${ }^{14}$

Volgens de wetgever dienen dus onder andere de artikelen 130 en $133 \mathrm{Fw}_{\mathrm{w}}$ in de wettelijke vereffening te worden toegepast. Dat is ten eerste opmerkelijk omdat ook aan die artikelen het fixatiebeginsel ten grondslag ligt, ${ }^{15}$ zodat de constatering dat de nalatenschap door een vereffening niet gefixeerd wordt zeker ter discussie kan worden gesteld. Ten tweede is opmerkelijk dat deze artikelen onderdeel uitmaken van dezelfde afdeling van de Fw als artikel 128 (afdeling 5 heeft als opschrift: 'Van de verificatie der schuldvorderingen') en net als laatstgenoemd artikel regelen of en voor welk bedrag de onderwerpelijke vordering in het faillissement geldend kan worden gemaakt. Er is gelet op de verwijzing in de parlementaire geschiedenis dus geen goede reden artikel 130 en 133 Fw wél, maar artikel 128 Fw níet toe te passen in de erfrechtelijke vereffening. Op zijn minst genomen constateer ik dat de wetgever artikel 128 Fw niet van overeenkomstige toepassing heeft uitgezonderd. ${ }^{16}$ Mijns inziens dient postume rente daarom in de wettelijke vereffening langs de meetlat van artikel $128 \mathrm{Fw}_{\mathrm{w}}$ te worden gelegd.

\subsection{Verschuldigdheid van rente?}

Die constatering heeft op zichzelf echter nog een aantal losse eindjes. Ten eerste de vraag wat dan het lot is van tijdens de vereffening vervallende rentetermijnen. Het hof overweegt dat 'geen wettelijke rente in rekening kan worden gebracht/verschuldigd is', terwijl de R-C stelt dat 'ook rente na de overlijdensdatum meegenomen dient te worden'. Deze zinsnedes maken niet helemaal duidelijk wat met die vordering dan gebeurt: ontstaat die niet? Mag of kan daar iets niet mee? Zijn de erfgenamen daarvoor niet aansprakelijk?

Het antwoord moet worden gevonden in het samenspel tussen artikel 4:182 lid 2, 4:184 lid 2 en 4:218 lid 5 BW. De na overlijden vervallende termijn doet een rentevordering ontstaan en de erfgenamen zijn daarvoor ingevolge artikel 4:182 lid 2 BW aansprakelijk. De nalatenschap, en niet het privévermogen van de erfgenamen, is daarvoor vervolgens verhaalsaansprakelijk ingevolge artikel 4:184 lid 2 BW. Bij het berekenen van de vordering is echter artikel $128 \mathrm{Fw}$ ingevolge artikel 4:218 lid 5 BW van overeenkomstige toepassing, zodat de nalatenschap slechts verhaalsaansprakelijk is voor zover de rentevordering door pand of hypotheek is gedekt. Voor het overige kan geen verhaal worden genomen op de nalatenschap noch op het privévermogen van de erfgenamen. In het geval een vereffenaar wordt benoemd terwijl ten minste één erfgenaam zuiver heeft aanvaard, is die erfgenaam naar rato van zijn erfdeel aansprakelijk (art. 4:182 lid 2 BW) én verhaalsaansprakelijk (art. 4:184 lid 2 sub a BW) voor de rentermijnen die na overlijden vervallen. Het is dus niet zo dat artikel 4:218 lid $5 \mathrm{BW}$ jo. artikel $128 \mathrm{FW}_{\mathrm{W}}$ tot gevolg heeft dat de rente niet verschuldigd wordt. ${ }^{17}$ Met behulp van artikel 4:184 BW kanaliseren en beperken zij slechts de verhaalbaarheid.

\subsection{Relevantie negatief saldo?}

Daarnaast valt op dat het hof in zijn argumentatie betrekt dat de nalatenschap een negatief saldo vertoont. Is dat dragend of noodzakelijk voor de conclusie dat de rente niet 'kan worden meegenomen' (beter: ter zake daarvan geen verhaal kan worden genomen op de nalatenschap)? Artikel 4:218 lid $5 \mathrm{BW}$ is op de vereffening van toepassing, ongeacht een eventueel positief saldo. Toegegeven kan worden dat de conclusie hier op het eerste gezicht enigszins merkwaardig voorkomt: ter zake van de rente kan gedurende de vereffening geen verhaal worden genomen, terwijl na de vereffening een surplus resteert.

11. Hof Amsterdam 28 maart 2017, ECLI:NL:GHAMS:2017:1031, r.o. 3.26.

12. Zie verder Asser/Perrick 4 2013/457.

13. Zie over de vraag of het fixatiebeginsel moet worden toegepast op de te vereffenen nalatenschap mijn aankomende bijdrage in WPNR alsmede Asser/Perrick 4 2017/632.

14. MvA II, Parl. Gesch. Boek 4 BW, p. 1014

15. Kortmann \& Faber, Geschiedenis van de faillissementswet, p. 126.

16. Anders: S.R. Baetens, De verschuldigdheid van rente bij de vereffening van nalatenschappen, REP 2018/79.

17. En dus al helemaal niet dat een zuiver aanvaardende erfgenaam een voordeel ten deel valt door toepassing van de vereffening. Anders: Baetens, De verschuldigdheid van rente bij de vereffening van nalatenschappen. 
Deze situatie kan op twee manieren worden opgelost. Ten eerste doet dit verschijnsel zich ook voor in faillissement, waar wordt aangenomen dat (1) de verjaringstermijn gedurende het faillissement niet ingaat, gelet op de niet-verifieerbaarheid, ${ }^{18}$ en (2) voor het verdelen van een surplus onder de schuldeisers die een niet-verifieerbare vordering hebben, bij gebreke aan een wettelijk voorschrift dat daar iets over bepaalt, een opvolgend faillissement dient te worden aangevraagd. ${ }^{19}$ Deze werkwijze lijkt mij goed toepasbaar op de wettelijke vereffening. Ten tweede, kijkend naar die vereffening, zijn de erfgenamen die een eventueel surplus ontvangen ingevolge artikel 4:184 lid $3 \mathrm{BW}$ verhaalsaansprakelijk met hun privévermogen tot de waarde die zij ontvangen. De nalatenschapsschuldeiser kan, bij een beneficiair aanvaarde nalatenschap, zijn rentevordering dus hetzij via een opvolgende vereffening, hetzij na een eventuele uitdeling bij de erfgenamen in privé verhalen. ${ }^{20}$

\subsection{Rente in lichte vereffening}

En hoe zit het dan tot slot met de 'lichte' vereffening door de (niet tot vereffenaar benoemde) erfgenamen? De in artikel 4:218 BW omschreven verplichtingen rusten slechts op hen wanneer de kantonrechter dat bepaalt. $^{21}$ Betekent dit dat de erfgenaam-vereffenaars een rentevordering anders moeten behandelen dan een benoemd vereffenaar, aangezien de behandelwijze van rentevorderingen voortvloeit uit artikel 4:218 lid 5 $\mathrm{BW} ?^{22}$ De verplichtingen waar het in artikel 4:221 BW over gaat, zijn blijkens de wetsgeschiedenis het oproepen van schuldeisers en het neerleggen en bekendmaken van de lijst met voorlopig erkende en betwiste vorderingen, de uitdelingslijst en de rekening en verantwoording. ${ }^{23}$ Het berekenen van vorderingen als bedoeld in artikel 4:218 lid 5 BW kan mijns inziens bezwaarlijk worden gezien als verplichting die niet behoeft te worden nageleefd; dat is juist de kern van de taak van de vereffenaars, benoemd of niet. De regels voor de behandeling van rentevorderingen gelden dus zowel in de 'zware' als in de 'lichte' vereffening.

\section{Conclusie}

De wet geeft mijns inziens antwoord op de vraag welke de behandeling is van rentevorderingen in de wettelijke vereffening van artikel 4:202 e.v. BW. Die vorderingen ontstaan, daarvoor zijn de erfgenamen aansprakelijk, en zij zijn daarvoor met het nalatenschapsvermogen verhaalsaansprakelijk voor zover die vordering door pand of hypotheek is gedekt. Als zij zuiver aanvaarden, zijn zij

18. HR 24 juni 2016, NJ 2016/497 m.nt. F.M.J. Verstijlen.

19. A.A.J. Smelt, Rente in faillissement: verificatie, verjaring en voldoening uit een boedeloverschot, Tvl 2017/4

20. Vgl. ook Parl. Gesch. Boek 4 BW, p. 1023

21. Art. 4:221 lid 1 BW.

22. Zie voor dit standpunt Baetens, De verschuldigdheid van rente bij de vereffening van nalatenschappen.

23. MvA II, Parl. Gesch. Boek 4 BW, p. 1024. Vgl. verder de Richtlijnen Vereffening nalatenschappen F.2. daarvoor onbeperkt in privé verhaalsaansprakelijk. Als een eventueel surplus resteert, kan de schuldeiser in kwestie een opvolgende vereffening verzoeken dan wel verhaal zoeken op het privévermogen van de erfgenamen die het surplus uitgedeeld krijgen, tot de waarde die de erfgenamen ontvangen. Daarbij is irrelevant of de nalatenschap een negatief saldo vertoont en of het een lichte of zware vereffening betreft.

Is - het voorgaande overziend - een vereffening dan écht meer een kunst dan een wetenschap? Het handjevol voorschriften in Boek 4 BW, voorzien van een schakelbepaling hier en daar naar de $F_{w}$, lijken weliswaar een abstracte richtlijn op hoofdpunten te geven, maar daarmee is, zeker als we die schakelbepalingen ter harte nemen en lering trekken uit het faillissementsrecht, in ieder geval op dit punt een sluitend systeem in het leven geroepen. 